\section{俩 Heighten Science \\ P U B L I C I T I O N S Corporation ISSN \\ 2576-9529}

\title{
Urine Leak Following Kidney Transplantation: An Evidence-based Management Plan
}

\author{
Shafiq A Chughtai ${ }^{1,2}$, Ajay Sharma ${ }^{2,3}$ and Ahmed Halawa ${ }^{2,4}$ \\ 'Department of Transplant and Hepato-Biliary Surgery, St James Hospital, Leeds, UK \\ 2Department of Medical Sciences, University of Liverpool, UK \\ ${ }^{3}$ Renal Transplantation Department, Royal Liverpool University Hospitals, UK \\ ${ }^{4}$ Renal Transplantation Department, Sheffield Teaching Hospitals, UK
}

*Address for Correspondence: Ahmed Halawa Consultant Transplant Surgeon, Sheffield Teaching Hospital, UK, Tel: +447787542128; Fax: +441142714604; Email: Ahmed.Halawa@sth.nhs.uk

Submitted: 24 September 2018

Approved: 01 October 2018

Published: 02 October 2018

Copyright: @ 2018 Chughtai SA. et al. This is an open access article distributed under the Creative Commons Attribution License, which permits unrestricted use, distribution, and reproduction in any medium, provided the original work is properly cited.

Keywords: Kidney transplantation; Urine leak Peri-graft collection; Lymphocele

\section{Abstract}

Care of kidney transplant recipient remains complex and long-term graft survival is not seen in every transplant recipient. Due to reduced supply and increased demand of human organs, more transplants are carried out using marginal grafts on emergency lists. Transplant recipients have altered physiology due to known end-stage renal disease, recent surgery and the use of potent analgesic and immunosuppressive medications. Amongst the known surgical complications, urine leak remains the most common. It can result from poor graft preparation due to excessive peri ureteric or lower pole dissection or damage to lower polar artery resulting in ischemic necrosis. In addition, poor surgical technique, bladder outflow obstruction, iatrogenic injury to bladder or renal pelvis may contribute to urine leak. Ongoing urine leak may manifest itself as swelling, pain, high drain output, sepsis, ileus and eventual graft loss. Early identification, localisation and quantification of leak remain essential in management of these patients. In addition, sepsis should be identified and treated promptly as these patients are highly susceptible to infections. Early recognition of this complication can significantly reduce hospital stay, improve quality of life and reduce graft loss and mortality. In this article, we aim to develop an evidence-based management approach to a patient with urine leak using a clinical scenario.

\section{Introduction}

Kidney transplantation is known to improve patient survival and reduce the cost of health care system significantly. According to kidney disease statistics for the United States, five years patient survival is $85.5 \%$ vs $35.8 \%$ in kidney transplant and dialysisdependent population. The cost to health care system is three times less compared to dialysis [1]. In the UK, as per the NHSBT organ donation report for 2014, the annual cost of dialysis is $£ 30,800$. Cost of kidney transplant in the first year is $£ 17,000$ falling to $£ 5000$ pa subsequently. A kidney transplant is a major undertaking in a physiologically compromised patient and complication in these patients have a significant effect on the eventual outcomes. The incidence of urological complications such has leak, obstruction and vesicoureteric reflux post-transplantation is quoted to be around $8 \%$ [2]. Older recipients, older donors, male gender and re-transplantation are risk factor for urological complications [3]. Urine leak remains the most common urological complication following kidney transplantation [4].

\section{Clinical Scenario}

A 28-year-old CKD 5 underwent kidney transplantation from his brother with primary graft function. Postoperatively, the drain output was $820 \mathrm{ml} /$ day on day 2 and $750 \mathrm{ml} /$ day on day 3 respectively. Drain fluid biochemistry showed potassium of 28 
$\mathrm{mmol} / \mathrm{L}$ and creatinine of $16000 \mu \mathrm{mol} / \mathrm{L}$. His serum creatinine was $416 \mu \mathrm{mol} / \mathrm{L}$, and $\mathrm{K}$ was $5.1 \mathrm{mmol} / \mathrm{L}$.

\section{Approach to patient following kidney transplantation}

The patient after kidney transplantation is initially nursed in the recovery and subsequently in intensive care, high dependency unit or the ward based on patient clinical condition and comorbidities. The patient is started on IV fluids and immunosuppressive medications as per the departmental protocol. She/he will have a dressing on the abdomen, a perinephric drain and a Foley's catheter. Vital signs are recorded along with hourly urine output. The drain is also monitored for volume and colour. In case of deterioration of vital signs as evident by worsening national early warning score (NEWS), care is escalated based on departmental protocols. Early postoperative complications include myocardial infarction, fluid overload, bleeding, vascular thrombosis, urine leak and wound dehiscence. It is vital that the patient is closely observed for any signs of clinical deterioration and appropriate steps are taken to stabilise and manage the patient.

In case of the example above, a patient who is in the early postoperative phase, clinically stable, with high volume drain output is likely to have urine leak. This is confirmed further by biochemical analysis of drain fluid which has shown high creatinine and potassium content when compared with serum. In our practice, we do send serum, urine and drain fluid for biochemistry simultaneously.

\section{Causes of fluid collection, clinical presentation and differential diagnosis}

Peri graft fluid collection (PFC) can be symptomatic or asymptomatic. In a retrospective study by Guerrero-Ramos et al, 300 deceased donor kidney transplant recipients were analysed. $31.4 \%(\mathrm{n}=93)$ has PFC. Complications were seen in $22.6 \%$ $(n=21)$ patients with PFC such as pain $(2 \%)$, infection $(3 \%)$, vascular $(4 \%)$ and ureteric complications (17\%). There was no difference between DBD (32\%) and DCD (30.8\%, p 0.9) recipients. The authors concluded that PFC are seen in up to a third of deceased donor kidney transplant recipients [5].

\section{Hematoma and bleeding}

It is important not to miss postoperative bleeding. Swelling can be noticed around the kidney scan, and blood can be seen in the drain. Immediately post-op, the patient may show signs of shock and drop of haemoglobin. None of these signs is diagnostic. Operative notes can provide helpful information. In a large study by Hechem et al., in 1203 patients with kidney transplantation were retrospectively studied for postoperative bleed over 12 years period using Toronto General Hospital database. The incidence of bleeding was $4.9 \%$. Risk factors were high BMI, use of anticoagulation and live donor kidney transplantation. Bleeding was associated with elevated risk of graft loss and death [6]. A slow bleed may result in hematoma formation. Unless a hematoma is infected, large or symptomatic, conservative management is the best option. It is important not to miss page kidney which is a large hematoma around kidney resulting in compromised perfusion. Any hematoma around kidney with a sudden drop in urine output requires prompt exploration to salvage the graft [7].

\section{Lymphocele}

Lymphocele is collection of lymphatic fluid around the kidney. The incidence $1-15 \%$ [8]. Few of lymphocele are symptomatic. It is argued that lymphocele arise from pelvic lymphatics of recipient injured during iliac vessel exposure or from donor kidney lymphatic from hilum. Risk of lymphocele formation increases with rejection, acute tubular necrosis and re-transplantation [9,10]. In symptomatic lymphocele, intervention is indicated. There are multiple methods. Percutaneous drainage alone is associated with high risk of recurrence. Prolong catheter drainage and sclerosant such 
as ethanol, povidone iodine, bleomycin, talcum and doxycycline has been employed with varying success $[11,12]$. It is important to realize that with use of sclerosant, there is a potential risk of paraurethral sclerosis [13]. Failure of conservative management is an indication of surgical intervention such as laparoscopic or marsupialization [14]. Careful ligation of lymphatic vessels in donor kidney and recipient pelvis can reduce the incidence of lymphocele.

\section{Abscess and infected collection}

Kidney transplant recipient who develops sepsis show inferior patient and graft survival [15]. Unfortunately, most kidney transplant recipients have poor physiological reserves, and in the presence of a compromised immune system, ongoing infection leads to disastrous results. A mycotic aneurysm in transplant vessels can develop and may require transplant nephrectomy [16]. It is a routine practice to send a sample for microscopy and culture of transplant perfusion fluid. An infected collection should be drained radiologically or surgically. Close observation of patient's inflammatory markers and regular imaging are always helpful. Antibiotic specific to pathogen should be started in consultation with the microbiology department.

\section{Urine leak}

Urine leak is the most common urological complication having an incidence range from 1.2 to $8.9 \%[2,4,17]$. Urine leak is occurring very early after the transplant is due to technical reasons which include anastomotic breakdown or iatrogenic injury to the bladder [18]. A kidney biopsy can cause injury to the renal pelvis and may also present as a urine leak [19]. The cause of delayed urine leak may be ischemic such as devascularisation of ureter during organ retrieval or injury to lower polar artery causing ureteric necrosis [17]. There is no firm evidence in favour of the routine use of the ureteric stent to prevent urine leak. Bzoma et al., investigated role of ureteric stenting and urological complication in kidney transplant recipients.628 recipients were included. Risk of urological complications were 10 times higher in non-stented group [20]. A systematic review by Thompson et al studied role of early vs late removal of ureteric stent in kidney transplantation. The authors concluded that early stent removal (up to day 15) is likely to reduce the incidence of UTIs, however its effect on major urological complication is unclear. Therefore, it can be argued that keeping ureteric stent for 6 weeks post transplantation might not be of benefit in all the transplant recipients and the decision to remove the stent should be individualized [21].

Urine retention can cause high pressures in the bladder causing reflux, hydronephrosis and urine leak. In all cases of urine leak, bladder outflow obstruction should be excluded [22] (Table 1).

\begin{tabular}{|c|c|c|c|}
\hline & & & \\
\hline Aetiology & Symptoms / Signs & Diagnosis & Management \\
\hline Hematoma & $\begin{array}{l}\text { Pain, swelling, hemodynamic } \\
\text { instability, high drain out-put. }\end{array}$ & $\begin{array}{c}\text { Fall in } \mathrm{Hb} \text {, } \\
\text { hyper-echoic collection on USS \& CT Scan } \\
(\text { Hounsfield Unit } \mathrm{HU}+50-+75)\end{array}$ & $\begin{array}{l}\text { Conservative if asymptomatic, Radiological / surgical } \\
\text { approach if active bleed or symptomatic. }\end{array}$ \\
\hline $\begin{array}{l}\text { Abscess / Infected } \\
\text { Collection }\end{array}$ & $\begin{array}{c}\text { Fever, Tachycardia, peri-graft } \\
\text { tenderness, swelling or No } \\
\text { symptoms. }\end{array}$ & $\begin{array}{c}\text { Raised Inflammatory markers. } \\
\text { USS/CT Peri-graft collection with septation and } \\
\text { debris. }\end{array}$ & Antibiotics with radiological or surgical drainage. \\
\hline Lymphocele & $\begin{array}{l}\text { Swelling, graft dysfunction, clear } \\
\text { drain output (high Volume) }\end{array}$ & $\begin{array}{c}\text { Biochemical analysis (urea and electrolytes- values } \\
\text { same as plasma). } \\
\text { Microscopy- Lymphocytes } \\
\text { USS/CT - anechoic collection }\end{array}$ & $\begin{array}{l}\text { If asymptomatic, no treatment needed. } \\
\text { If causing pain or compression of surrounding viscus, } \\
\text { percutaneous/radiological/surgical drainage. }\end{array}$ \\
\hline Urinoma & $\begin{array}{c}\text { Pain, swelling, fever, high drain } \\
\text { output. }\end{array}$ & $\begin{array}{l}\text { Biochemical analysis- Blood, drain fluid and urine } \\
\text { simultaneously check for urea, creatinine and } \\
\text { electrolytes. } \\
\text { USS/Non-contrast CT - anechoic/ Septated } \\
\text { collection }\end{array}$ & $\begin{array}{c}\text { Small volume - decompress bladder, drain collection and } \\
\text { observe. } \\
\text { Large volume- as above, percutaneous nephrostomy / } \\
\text { surgical options to be considered. }\end{array}$ \\
\hline
\end{tabular}




\section{Diagnostic approach to urine leak}

Urine leak can be early or late and may manifest in different ways. Our approach to patients with suspected urine leaks includes following steps.

- Send drain fluid for biochemistry, microbiology and culture.

- Send urine and serum samples at the same time for biochemical analysis.

- Place urinary catheter and monitor urine output.

- Confirm urine leak. High creatinine and potassium content in drain fluid. (Values close to urine and not serum).

- Arrange ultrasound scan and/or CT depending upon departmental preference. Caution should be exercised in use of contrast CT to prevent graft nephropathy. If bladder leak is likely, cystogram is useful.

- In cases where diagnosis is difficult, radionuclide imaging such as Tc $99 \mathrm{~m}$ or MAG 3 scan can be employed. The radionucleotide is concentrated and then excreted by the kidney revealing functional and excretory status of the graft. Hold of contrast in renal bed is diagnostic of urine leak.

\section{Management of urine leak}

- Initial Step: In all patients with urine leak, patient should be stabilized by ensuring euvolemia, excluding sepsis and the need for dialysis.

- Small Leak: If urine is coming via Foleys and the size of urinoma is small, maximum decompression should be employed. This includes prolong catheter drainage, leaving ureteric stent for longer period and radiological drainage of perinephric collection $[23,24]$.

- Hydronephrosis or Large Leak: The presence of hydronephrosis on imaging indicates an obstruction. Percutaneous nephrostomy is the next option to allow immediate decompression [22]. In addition, a nephrostogram can diagnose ureteric obstruction, localise and quantify urine leak, and exclude intraperitoneal leak. The nephrostomy is generally left for 6 weeks, and the patient is closely monitored for drain output and graft function. After 6 weeks, nephrostogram is performed to exclude leak, followed by clamping of nephrostomy and removal after 48 hours if urine output and graft function remained stable. Percutaneous insertion of the nephrostomy tube can cause bleeding and subsequent ureteric obstruction. This can be successfully managed conservatively by urokinase instillation in the majority of cases [23].

- Monitoring Conservative Management: Successful management is indicated by falling output through the percutaneous nephrostomy and perinephric drain with the simultaneous increasing output from bladder catheter. If the cause is a distal obstruction, such as bladder outflow obstruction, blocked stent or kinking of the ureter, the appropriate next step should be employed.

\section{- Surgical Intervention:}

o In cases where conservative management fails, open exploration is indicated.

o It is important to realize that intraperitoneal rupture of bladder in nontransplant patient is an indication for surgery although there is no consensus in this regard [25]. Peritoneum can be breached during transplant surgery and in recipients where urine leak is intraperitoneal, open repair remains a sensible option. We managed successfully a case of early large volume intraperitoneal 
urine leak with ureteric re implantation. Patient developed prolong ileus, wound dehiscence and sepsis in early post-operative phase however responded well to surgery.

\section{- $\quad$ Surgical Options [26]}

Surgical option is considered as a last resort in most patients with urine leaks. Surgery puts the recipient and the graft at risk and is technically demanding due to scarring. Early surgical intervention can be technically easier compared delayed intervention. Tension-free ureteric anastomosis and preservation of the vascularity of the transplanted ureter are crucial.

Re-do anastomosis using donor ureter and recipient's bladder: If the length of the remaining ureter is adequate, redoing the anastomosis is best option.

Using the native ureter for anastomosis: In case where the donor ureter cannot be used for anastomosis (too short), native ureter can be anastomosed to renal pelvis of the renal graft.

Using native bladder to gain length - Boari flap/Psoas Hitch: In cases where anastomosis is under tension, a psoas hitch or a Boari flap can be employed with satisfactory results (Figures 1,2).

\section{Imaging in perinephric collection}

Various imaging modalities are available to assess perinephric collection. Ultrasound is most readily available and cheapest option. It is quick and cost-effective. However, in post-operative patients, there is an element of ileus resulting from gaseous dilation of the bowel. Dressings and patient discomfort further limit the utility of ultrasound. In carefully selected cases, ultrasound can assess renal perfusion, exclude hydronephrosis and perinephric fluid collections. CT scan has a better diagnostic yield however it requires the patient to be transported to the radiology department and exposed to radiation. Also, contrast administration causes kidney injury. Non- contrast CT can differentiate blood from urine as former is of high density (60-90 Hounsfield Units) [23] (Figures 3-5).

Nephrostogram is a valuable tool to define the extent of leak and level of obstruction in kidney transplant recipient. In cases where doubt exist regarding presence of urinoma, by radionucleotide scan can be a helpful investigation in the context of a perinephric collection [28] (Figure 6).

$9 \mathrm{~m}$ Scintigraphy demonstrating urine leak from uretero-pelvic junction of Transplant Kidney [29].

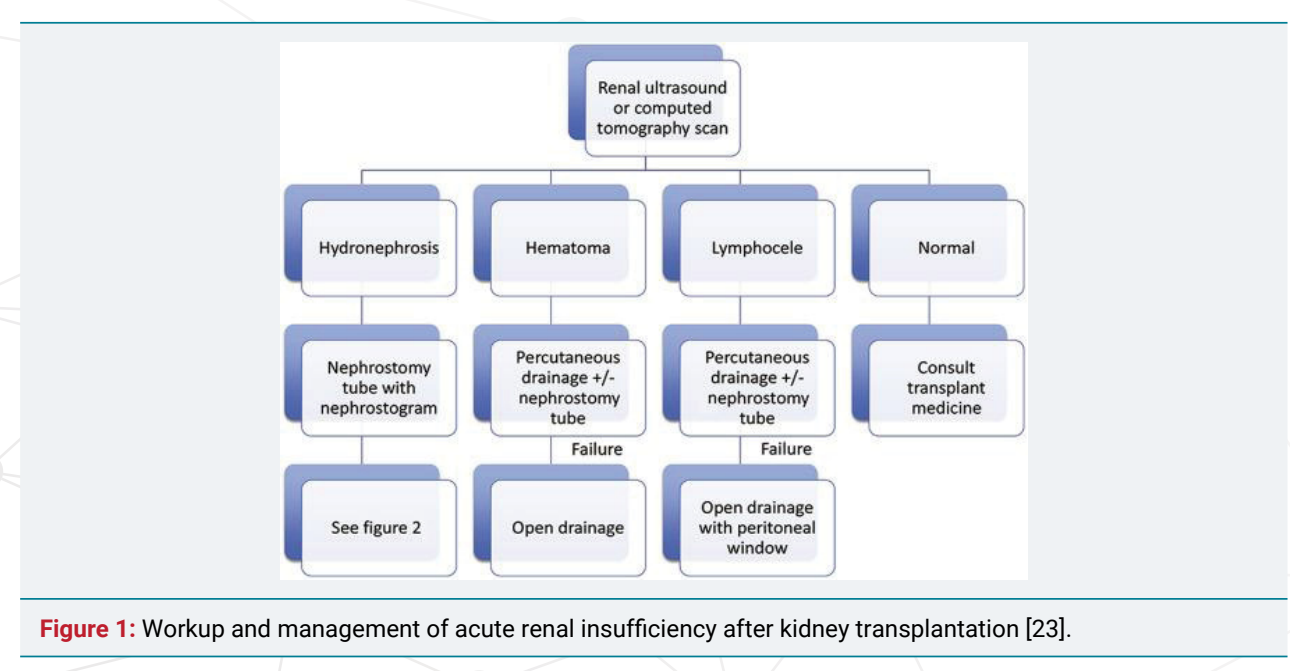




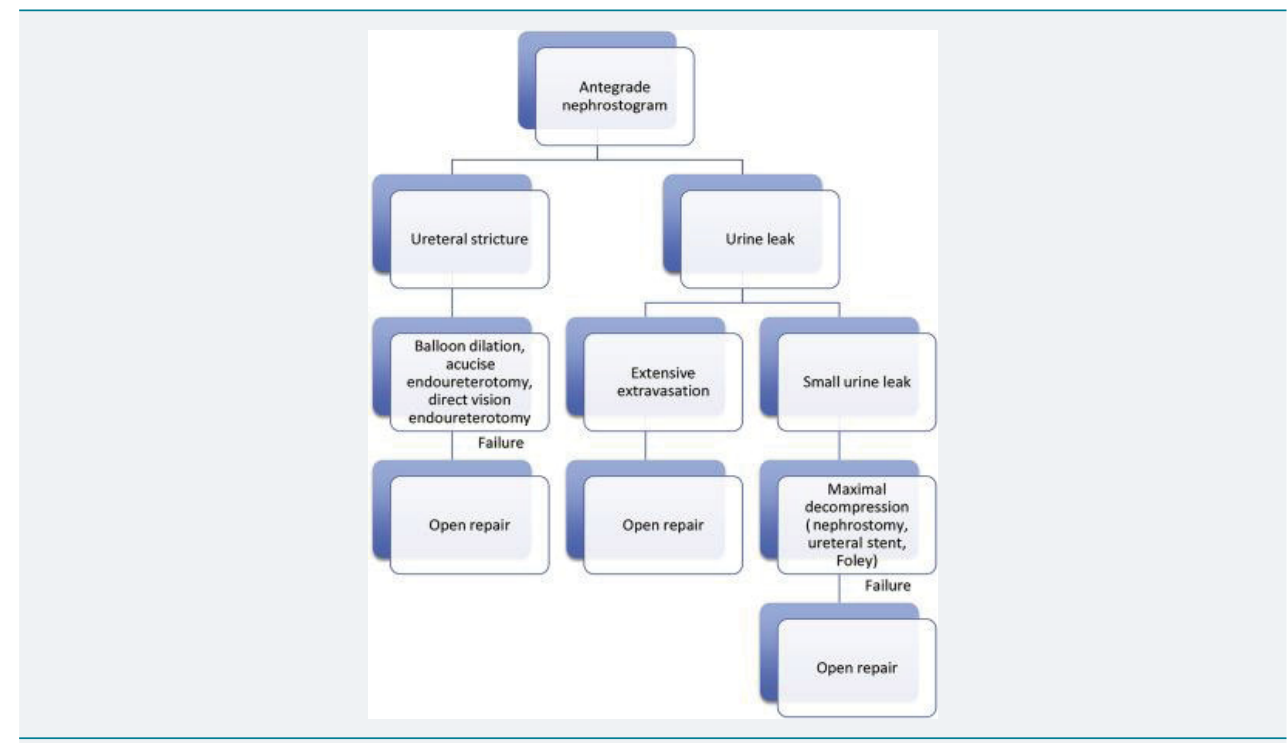

Figure 2: Workup \& Management of Transplant Ureteral Complications [23]

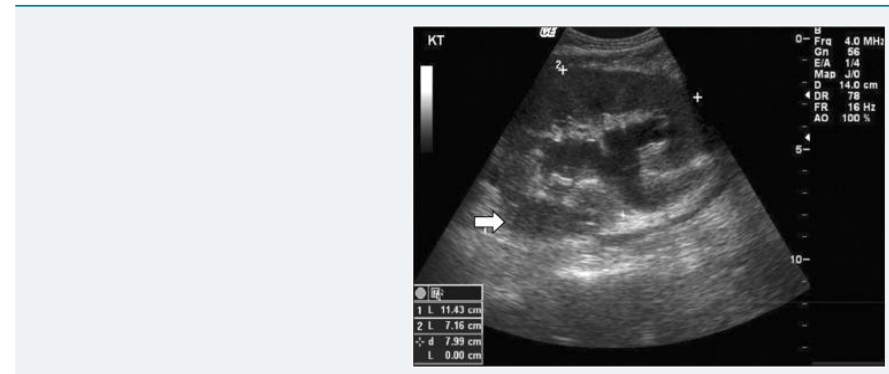

Figure 3: Ultrasound demonstrating hydronephrosis and perirenal fluid collection (White arrow) [27].

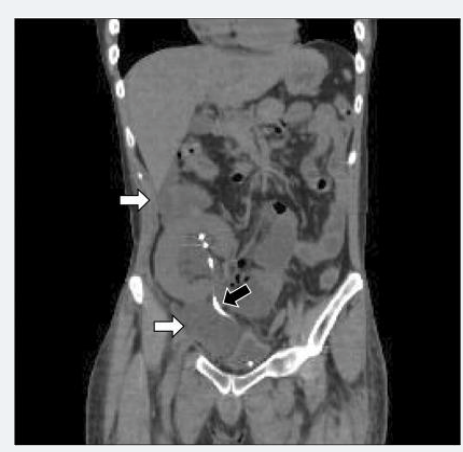

Figure 4: CT demonstrating peri renal and pelvic fluid collection (White Arrow) and Double J stent (Black Arrow) [27].

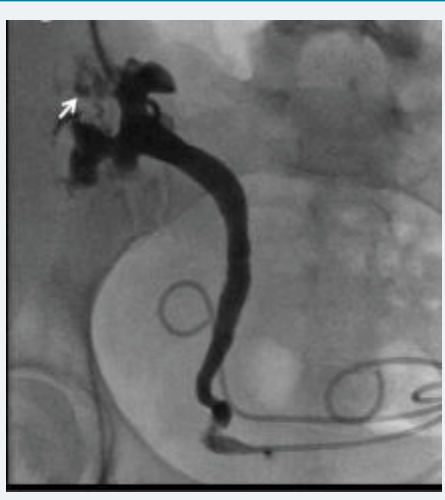

Figure 5: Nephrostogram demonstrating leak from upper renal calyceal system and dilated proximal ureter [28] 


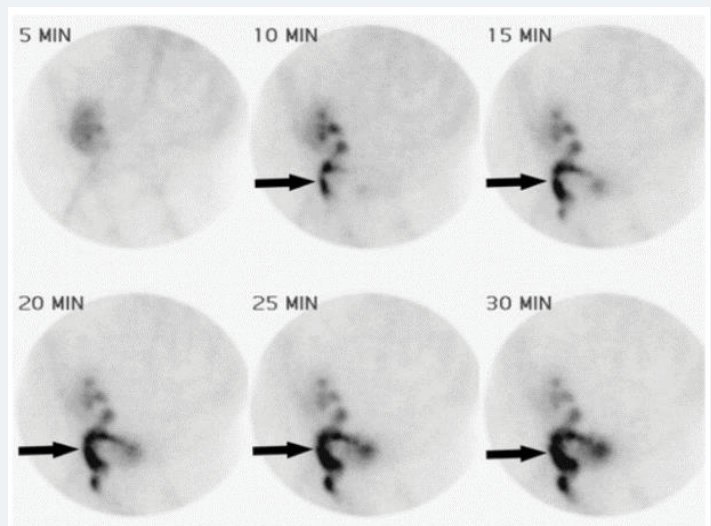

Figure 6: Tc 99 m Scintigraphy demonstrating urine leak from uretero-pelvic junction of Transplant Kidney [29].

Radionucleotide scan such as Tc99m Scintigraphy and Mercapto-acetyl-triglycine (MAG3) is a useful scan which can diagnose urine leaks in equivocal cases. Hold up of the contrast around kidney is diagnostic of urine leak [29,30].

\section{Application to the indexed case}

Our patient has increased drain output and evidence of primary graft function. The biochemical analysis of drain fluid is close to urine, hence suggesting urine leak. The patient requires standard post-operative management such as adequate analgesia, fluid replacement and graft monitoring. Patient should be monitored for any signs of sepsis and antibiotics should be started early. CT scan without IV contrast will confirm the extent of leak and presence of urinoma.

In case there is no hydronephrosis, urinoma can be drained radiologically, ureteric stent and Foley's catheter can be left for a longer period.

If there is hydronephrosis, a percutaneous nephrostomy and nephrostogram should be done and nephrostomy left in situ for six weeks. If nephrostogram demonstrates distal obstruction, antegrade or retrograde stenting remains a viable option depending upon the extent of obstruction and local expertise available.

If the imaging demonstrates complete distal obstruction not amenable to stenting or a large volume leak and sepsis which is not responding to medical management, surgical re-exploration is warranted.

\section{Conclusion}

Urine leak after kidney transplantation presents with swelling, pain, increased drain output and worsening graft function.

These patients should be kept under close monitoring, sepsis should be excluded, and Foley's catheter inserted. Drain fluid and Foley's output should be monitored. The drain fluid should be analyzed for creatinine and potassium level with concomitant biochemical analysis of urine and serum.

Localization of leak should be based on ultrasound, CT scan, radionuclide scan or percutaneous nephrostogram. A small leak is managed with long-term Foley's catheter, ureteric stent and radiological drainage of urinoma. Large leaks are managed with percutaneous nephrostomy, ante grade or retrograde stenting, radiological drainage of urinoma and with or without surgery.

Failure of conservative management is an indication of surgery. Many options exist and depend on patient's fitness for surgery, the anatomy of leak and the length of the available ureter. 


\section{References}

1. National Institute of Diabetes and Digestive and Kidney Diseases. Kidney Disease Statistics for the United States. 2018; Ref.: https://goo.gl/ZwXe22

2. Lempinen J, Stenman J, Kyllonen L, Salmela K. Surgical Complications following 1670 consecutive adult renal transplantations: a single center study. Scand J Surg. 2015;104: 254-259. Ref.: https://goo.gl/9amz93

3. Neri F, Tsivian M, Coccolini F, Bertelli R, Cavallari G, et al. Urological complications after Kidney transplantation: experience of more than 1000 transplantations. Transplant Proc 2009; 41:1224 1226. Ref.: https://goo.gl/8zmZti

4. Streeter EH, Little DM, Cranston DW, Morris PJ. The urological complications of renal transplantation: a series of 1535 patients. BJU Int. 2002; 90: 627-634. Ref.: https://goo.gl/fSauZE

5. Guerrero-Ramos F, Cavero-Escribano T, Rodríguez-Antolín A, Andrés-Belmonte A, Passas-Martínez $\mathrm{J}$, et al. Perigraft fluid collections after kidney transplantation: Does the type of donor (uncontrolled donation after circulatory death vs. donation after brain death) have a role? Cent European $\mathrm{J}$ Urol. 2017; 70: 439-444. Ref.: https://goo.gl/fhP8Jd

6. Hachem LD, Ghanekar A, Selzner M, Famure O, Li Y, et al J. Postoperative surgical-site haemorrhage after kidney transplantation: incidence, risk factors, and outcomes. Transpl Int. 2017; 30: 474-483. Ref.: https://goo.gl/RVNurw

7. Chung J, Caumartin Y, Warren J, Luke PP. Acute Page kidney following renal allograft biopsy: a complication requiring early recognition and treatment. Am J Transplant. 2008; 8: 1323-1328. Ref.: https://goo.gl/beuYs9

8. Humar A, Matas AJ. Surgical complications after kidney transplantation. Semin Dial. 2005;18: 505510. Ref.: https://goo.gl/pxR9vd

9. Fuller TF, Kang SM, Hirose R, Feng S, Stock PG. et al. Management of lymphocele after renal transplantation: laparoscopic vs open drainage. J Urol. 2003; 169: 2022-2025. Ref.: https://goo.gl/2yMCBp

10. Langer RM, Kahan BD. Incidence, therapy and consequence s of lymphocele after sirolimuscyclosporine-prednisone immunosuppression in renal transplant recipients. Transplantation 2002; 74: 804-808. Ref.: https://goo.gl/RYco3z

11. Zukerman DA, Yeager TD. Percutaneous ethanol sclerotherapy of postoperative lymphocele. AJR Am J Roentgenol. 1997; 169: 433-437. Ref.: https://goo.gl/JKbQtJ

12. Chandrasekaran D, Meyyappan RM, Rajaraman T. Instillation of povidone iodine to treat and prevent lymphocele after renal transplantation. BJU Int. 2003; 91: 296. Ref.: https://goo.gl/xjqeLJ

13. Manfro RC, Comerlato L, Berdichevski RH, Ribeiro AR, Denicol NT, et al. Nephrotoxic acute renal failure in a renal transplant patient with recurrent lymphocele treated with povidone-iodine irrigation. Am J Kidney Dis. 2002; 40: 655-657. Ref.: https://goo.gl/rrZnBb

14. Bzoma B, Kostro J, Dębska-Ślizień A, Hellmann AR, Zadrożny D, et al. Treatment of the Lymphocele After Kidney Transplantation: A Single-center Experience. Transplant Proc. 2016; 48: 1637-1640. Ref.: https://goo.gl/f9Z4iG

15. Schachtner $T$, Stein $M$, Reinke $P$. Sepsis after renal transplantation: Clinical, immunological, and microbiological risk factors. Transpl Infect Dis 2017; 19. Ref.: https://goo.gl/yJfsVi

16. Ministro A, Ferreira T, Batista L, Santana A, Alves N, et al. Mycotic Pseudoaneurysm After Kidney Transplantation: Two Case Reports. Transplant Proc. 2017; 49: 906-912. Ref.: https://goo.gl/uUE1UG

17. Nie ZL, Zhang KQ, Li QS, Jin FS, Zhu FQ, et al. Treatment of urinary fistula after kidney transplantation. Transplant Proc. 2009; 41: 1624-1626. Ref.: https://goo.gl/iU87kT

18. Mah TJ, Mallon DH, Brewster O, Saeb-Parsy K, Butler AJ, et al. Ureteric complications in recipients of kidneys from donation after circulatory death donors. Clin Transplant. 2017; 31. Ref.: https://goo.gl/3v3sqP

19. Ham YR, Moon KR, Bae HJ, Ju HJ, Jang IK,et al. A Case of Urine Leakage: An Unusual Complication after Renal Biopsy. Chonnam Med J. 2011; 47: 181-184. Ref.: https://goo.gl/c39b5W

20. Bzoma B, Kostro J, Hellmann A, Chamienia A, Hać S, et al. Ureteric Stenting in Kidney Transplant Recipients, Gdansk Centre Experience, Poland. Transplant Proc. 2018; 50: 1858-1862. Ref.: https://goo.gl/5ZGQm6

21. Thompson ER, Hosgood SA, Nicholson ML, Wilson $\mathrm{CH}$. Wilson $\mathrm{CH}$. Early versus late ureteric stent removal after kidney transplantation. Cochrane Database Syst Rev. 2018; 1: CD011455. Ref.: https://goo.gl/JAq67V 
22. Singer J, Gritsch HA, Rosenthal JT. The transplant operation and its surgical complications. In: Danovitch GM, ed. Handbook of Kidney Transplantation.5th ed. Philadelphia, PA, Lippincott Williams \& Wilkins; 2005: 193-212.

23. Duty BD, Barry JM. Diagnosis and management of ureteral complications following renal transplantation. Asian J Urol. 2015; 2: 202-207. Ref.: https://goo.gl/i9Xp3A

24. Duty BD, Conlin MJ, Fuchs EF, Barry JM. The current role of endourologic management of renal transplant complications. Adv Urol. 2013; 246520. Ref.: https://goo.gl/eG2ny9

25. Craggs $B$, Michielssen D. Conservative treatment of an intraperitoneal bladder perforation. Cent European J Urol. 2011; 64: 47-49. Ref.: https://goo.gl/Bdh5pD

26. Burks FN, Santucci RA. Management of iatrogenic ureteral injury. Ther Adv Urol 2014; 6: 115-124. Ref.: https://goo.gl/1uX9K7

27. Yap R, Madrazo B, Oh HK, Dienst SG. Perirenal fluid collections after kidney transplantation. Chonnam Med J. 2012; 48: 57-59. Ref.: https://goo.gl/izQ1KR

28. Kumar S, Ameli-Renani S, Hakim A, Jeon JH, Shrivastava S, et al. Ureteral obstruction following renal transplantation: Causes, Diagnosis and Management. Br J Radiol. 2014; 87: 20140169. Ref.: https://goo.gl/y7XZFp

29. Titton RL, Gervais DA, Hahn PF, Harisinghani MG, Arellano RS, et al. Urine leaks and urinomas: diagnosis and imaging-guided intervention.Radiographics. 2003; 23: 1133-1147. Ref.: https://goo.gl/zRDSXZ

30. Poyraz NY, Ozdemir E, Keskin M, Türkölmez S. Additional Value of SPECT/CT to Tc-99m MAG3 Renal Scintigraphy in the Diagnosis of a Patient with Ureteroileal Fistula. Mol Imaging Radionucl Ther. 2012; 21: 84-87. Ref.: https://goo.gl/giQaRB 